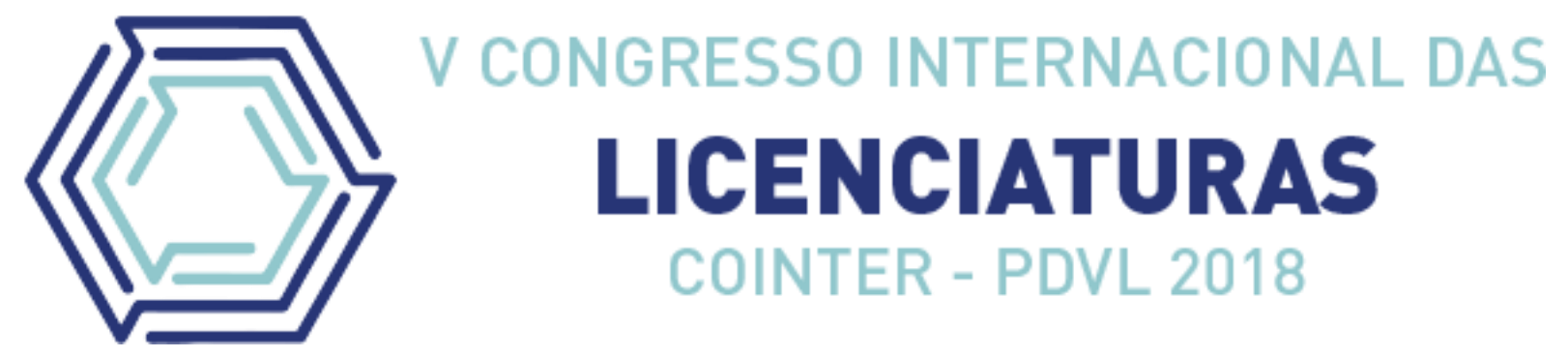

\title{
CICLO DA EXPERIÊNCIA KELLYANA: IMPORTANCIA DA UTILIZAÇÃO DO CEK ALIADO A EXPERIMENTAÇÃO PARA A FORMAÇÃO DE ESTUDANTES DO ENSINO MÉDIO NA DISCIPLINA DE QUÍMICA.
}

\section{CYCLE OF THE KELLYANA EXPERIENCE: IMPORTANCE OF THE USE OF CEK ALLIED TO EXPERIMENTATION FOR THE TRAINING OF STUDENTS OF MIDDLE SCHOOL IN THE CHEMISTRY DISCIPLINE.}

\author{
Apresentação: Pôster \\ Palloma Joyce de Aguiar Silva ${ }^{1}$; Rayanne da Silva Lima²; Flávio José de Abreu \\ Moura $^{3}$; Josefa Luana da Silva Sousa ${ }^{4}$; Kilma da Silva Lima Viana ${ }^{5}$

\section{DOI: https://doi.org/10.31692/2358-9728.VCOINTERPDVL.2018.00188}

\section{Introdução}

Sabemos que quando o assunto é a química, é possível notar uma grande evasão pela área, onde se tratando da área da docência ainda acaba sendo maior. Na maioria das vezes, no espaço escolar encontramos estudantes com grandes índices de dificuldades acerca da disciplina de química, onde esses fatos na maioria das vezes podem ser atribuídos às estratégicas tradicionais de ensino, que aliadas aos conteúdos complexos tornam as aulas monótonas e desestimulantes. Sabendo que a utilização de experimentos, aliado ao aprendizado de determinados conteúdos e atividade mais dinâmica, acabando despertando o interesse dos estudantes nos conteúdos discutidos em sala de aula, e podendo ser levados para o cotidiano, proporcionando uma aprendizagem eficaz, divertida e empolgante, porem, na maioria das vezes, os estudantes relatam a grande ausência das aulas experimentais, sendo justificados pelos professores devido à falta de espaço, materiais e muitas das vezes a preparação dos próprios professores, assim, dificultando no processo de ensino e

\footnotetext{
${ }^{1}$ Licenciatura em Química, Instituto Federal de Pernambuco, palloma joyce_aguiar@hotmail.com

${ }^{2}$ Licenciatura em Química, Instituto Federal de Pernambuco, rayannelima-@hotmail.com

${ }^{3}$ Licenciatura em Química, Instituto Federal de Pernambuco, flavio.jose33@hotmail.com

${ }^{4}$ Licenciatura em Química, Instituto Federal de Pernambuco, lu.souza@hotmail.co,

${ }^{5}$ Doutora em Ensino de Ciências e Matemática (UFRPE), docente, Departamento de Desenvolvimento Educacional, Instituto Federal de Educação, Ciências e Matemática (IFPE), IFPE-campus Vitória de santo antão, kilma.viana@vitoria.ifpe.edu.br
} 
aprendizagem dos estudantes.

Neste trabalho apresentamos os resultados de uma investigação sobre as contribuições do Ciclo da Experiência Kellyana (CEK), como instrumento metodológico, para promover uma revisão construtiva, na estrutura cognitiva dos estudantes, da relação a conteúdos de química. Onde Kelly (1963) considera que os seres humanos, ao se depararem com diversas situações ou eventos, tendem a selecionar certas características, o que ele chama de construto. $\mathrm{Na}$ maioria das vezes, a experimentação acaba sendo auxiliadora no processo do conhecimento empírico para o teórico, Kelly (1963) desenvolveu trabalhos com relação à aprendizagem, adotando uma postura construtivista, vendo o homem como um cientista, sempre prevendo e antecipando eventos. Segundo Kelly (1963), os seres humanos constroem sua realidade na qual respondem, e sua resposta está direcionada pelas suas experiências, utilizando conceitos prévios similares para antecipar as consequências do comportamento (HALL; LINDZEY; CAMPBELL, 2000).

O presente trabalho tem como o principal objetivo destacar a principal importância da utilização do CEK aliadas a praticas experimentais, por meio de intervenções realizadas por meio do PDVL - PROGRAMA INTERNACIONAL DESPERTANDO VOCAÇÕES PARA LICENCIATURAS, pelas estudantes do Gt de Experimentação, onde vem sido notado a grande contribuição desta metodologia no ensino da química, com estudantes de ensino médio da Escola Antônio Dias Cardoso, na cidade de Vitória de Santo Antão, Pernambuco. Destacando que todas as intervenções são realizadas pelo Ciclo da Experiência Kellyana.

\section{Fundamentação Teórica}

Mesmo com todo o avanço nos dias atuais, com a modernização, muitos professores em pleno século 21 ainda continuam adotando metodologias completamente tradicionais, onde acabam afastando os estudantes cada vez mais, se tratando de química, isso não é algo diferente, pois a química é uma ciência fundamental que encontramos com uma grande escala no nosso cotidiano, como relata o próprio onde Valadares (2001) deixa destacado que as aulas de química costumam ser assimiladas pelos educandos como algo distante, os quais na maioria das vezes não sabem o objetivo do conteúdo que estão estudando, isso acaba levando os alunos a uma apatia pela matéria desestimulando-os, resultado que também atinge os professores que percebem o distanciamento dos alunos em relação à matéria. 
Onde pensando como Filho (2011), somente quando o estudante vê significado no que está estudando é que ele consegue compreender e produzir o saber. Daí a importância de fazer o conteúdo ter sentido para o estudante aprender. Porem, não é novidade, que no ensino médio, os estudantes apenas acabam assistindo as aulas de química de uma maneira passiva, onde todos os seus conhecimentos prévios na maioria das vezes são por completos descartados. Para tanto, Kelly (1963) desenvolveu trabalhos com relação à aprendizagem, adotando uma postura construtivista, vendo o homem como um cientista, sempre prevendo e antecipando eventos. Para Kelly (1963), “os processos de uma pessoa são psicologicamente canalizados pelas maneiras por meio das quais ela antecipa eventos", nisto, sendo importantes os conhecimentos prévios dos estudantes para a construção de novos conhecimentos.

Kelly (1955) defende que a aprendizagem não é algo especial que acontece apenas nas escolas, ou em algumas ocasiões, mas um processo diretamente ligado à vivência de uma experiência (LIMA, 2008). E essa experiência acontece a partir de um ciclo que apresenta cinco (5) etapas, que estão especificadas abaixo:

\section{- Antecipação;}

- Investimento;

- Encontro;

- Confirmação ou desconfirmação;

- Revisão construtiva.

\section{Metodologia}

A natureza deste trabalho é de caráter qualitativo, que por meio de intervenções realizadas pelo Ciclo da experiência Kellyana- CEK, com cinco etapas;

- Antecipação: Momento em que a pessoa usa os construtos que possui no seu sistema de construção e tenta antecipar um evento que está prestes a acontecer.

- Investimento: Momento de se preparar para se encontrar com o evento, ou seja, melhorar a construção da réplica através da introdução de novos saberes.

- Encontro: Momento de se deparar com o evento que antecipou.

- Confirmação ou desconfirmação: Momento de confirmar ou desconfirmar suas hipóteses iniciais através da vivência no evento.

- Revisão construtiva: Momento de reconstruir seus construtos. 
Onde os principais sujeitos dessas intervenções são estudantes de Ensino médio, da Escola de Referência Dias Cardoso, onde trabalhamos com estudantes do $1^{\circ}$ Ano do Ensino Médio, com turmas de 30 alunos, D e E, com acompanhamento da professora nas realizações das atividades experimentais.

\section{Resultados e Discussões}

Com base nas intervenções realizadas, foi notório a grande contribuição no a processo de ensino e aprendizagem dos estudantes por meio da utilização do CEK nas aulas de química.

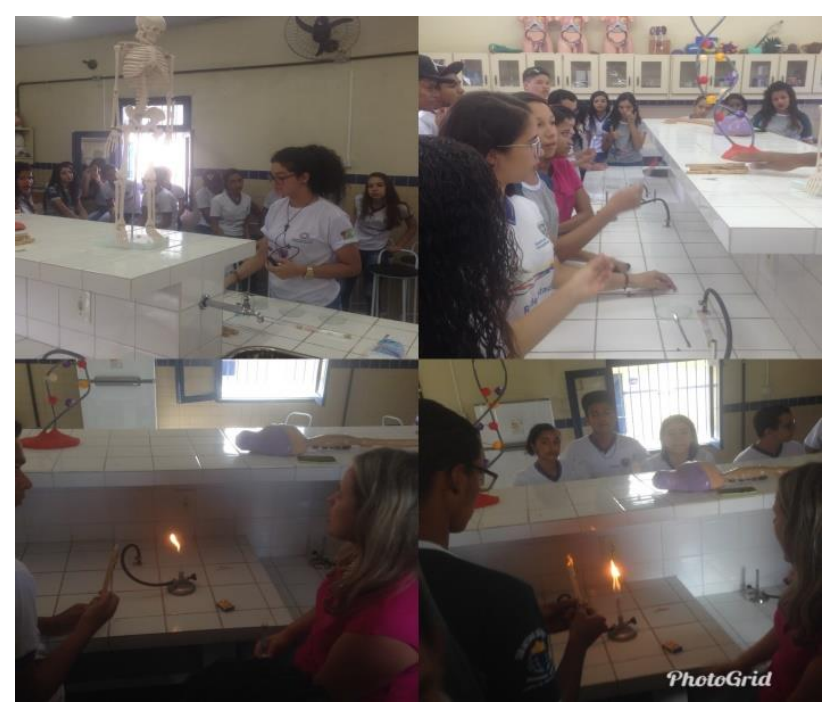

\section{Imagem 1: Fonte Própria.}

Referente a imagem 1, relacionado a intervenção com experimento relacionado ao experimento de "testes de chamas", relacionado ao conteúdo de teste chamas, onde os próprios estudantes relataram que a metodologia utilizada foi auxiliadora no processo de aprendizagem, onde os mesmo relatam que conseguiram reforçar um conhecimento já existente.

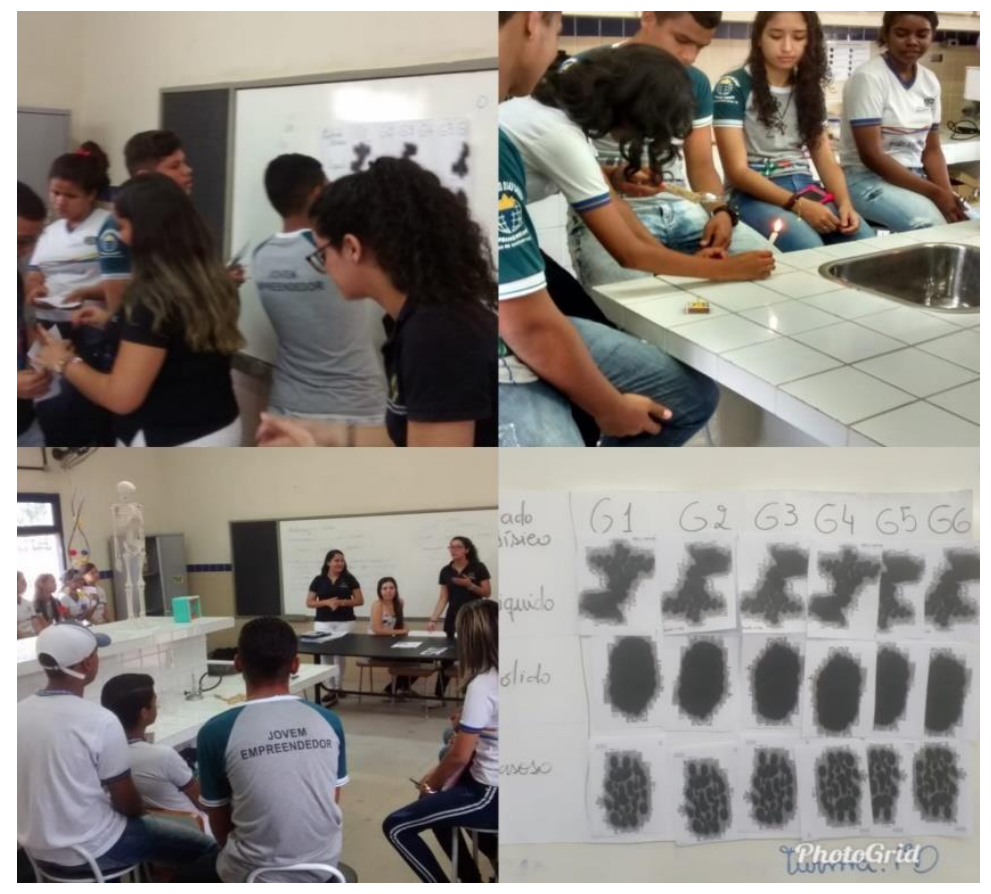




\section{Imagem 2: Fonte própria.}

Com base na segunda intervenção, sobre as mudanças de estados da naftalina com base na imagem 2, os estudantes também relataram a grande satisfação em participar das aulas, onde eles conseguiram participar e também associar os conceitos ao cotidiano, onde tiverem a chance de opinar.

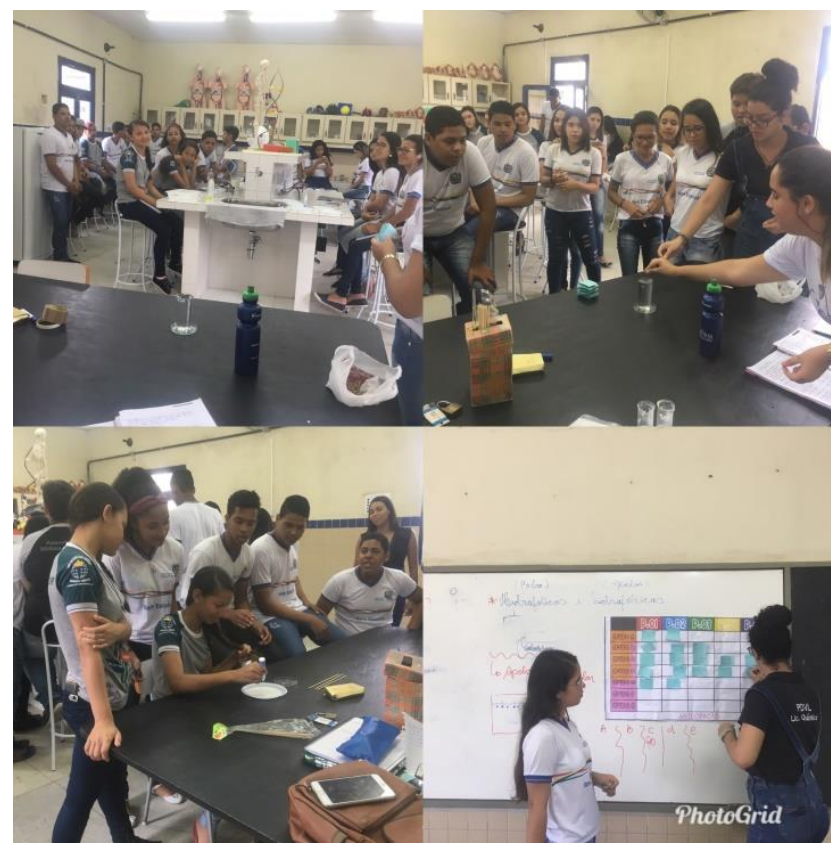

Imagem 3: Fonte Própria.

$\mathrm{Na}$ terceira intervenção, referente ao conteúdo de tensão superficial, onde seguimos trabalhando com o CEK, onde mais uma vez os estudantes permaneceram com seus elogios acerca da metodologia, pois relataram a compreensão do conteúdo de tensão, e que tiveram a chance de participarem e além domais contribuir na aula, pois ainda foi destacado o quão foi importante o reconhecimento das suas opiniões, e que tiveram a chance de reavaliar suas respostas e pensamentos sobre o conteúdo.

\section{Conclusões}

Os conhecimentos adquiridos pelos estudantes por meio da metodologia utilizada, CEK, podem ser utilizados durante o processo de ensino e aprendizagem para que, eles mesmos, possam reestruturar novos conceitos. A aplicação de questionários pré e pós podem auxiliar o professor na investigação de conceitos desenvolvidos durante as atividades. Onde, é importante salientar que todo o processo metodológico, segundo os estudantes, nas intervenções realizadas até o momento, foi de grande valia para os mesmo. 
Pois com bases dos comentários das intervenções, os estudantes relataram a grande contribuição no seus aprendizados, destacando a importância da experimentação nas aulas de química, quando aliada ao CEK, podendo reconstruir os conhecimentos pérvios, e tendo a passagem do conhecimento empírico para o teórico. Também contribuindo na formação dos próprios discentes de licenciatura em química.

\section{Referências}

FILHO, F. S. L; CUNHA, F. P.; CARVALHO, F. S.; SOARES, M. F. C. A importância do uso de recursos didáticos alternativos no ensino de química: Uma abordagem sobre novas metodologias. ENCICLOPÉDIA BIOSFERA, Centro Científico Conhecer - Goiânia, vol.7, N.12; 2011.

HALL. C. S.; LINDZEY, G.; CAMPBELL, J. B. Teorias da personalidade. 4. ed. Porto Alegre: Artmed, 2000.

LIMA, K. S. Compreendendo as concepções de avaliação de professores de física através da teoria dos construtos pessoais. Recife, 2008. 163 p. Dissertação (Ensino das Ciências). Departamento de Educação, UFRPE, 2008.

KELLY, G. A. A theory of personality: the psychology of personal constructs. New York: Norton, 1963.

VALADARES, Jorge (2001) - Abordagens construtivistas e investigativas à actividade experimental - Comunicação oral no IV Encontro Nacional de Didácticas e Metodologias da Educação- Percursos e Desafios, Universidade de Évora, 2001. 